\title{
Elastic Stable Intramedullary Nailing for Closed Diaphyseal Fractures of Humerus in Adults. A Case Series of 28 Patients
}

\section{Bahaa A Kornah ${ }^{1}$, Abdel-Aleem Soltan ${ }^{2}$ and Mohamed A Abdel-AA ${ }^{3 *}$}

${ }^{1}$ Department of Orthopedic Surgery, Faculty of Medicine, Al-Azhar University, Cairo, Egypt

${ }^{2}$ Department of Orthopedic Surgery, Faculty of Medicine for Girls, Al-Azhar University, Cairo, Egypt

${ }^{3}$ Department of Orthopedic Surgery, El-Bakry General Hospital, Ministry of Health, Cairo, Egypt

*Corresponding author: Mohamed A. Abdel-AAl, Department of Orthopedic Surgery, El-Bakry General Hospital, Ministry of Health, Cairo, Egypt, Tel: +01020995024; Email: btmnail2010@hotmail.com

Rec date: July 30, 2017; Acc date: November 03, 2017; Pub date: November 06, 2017

Copyright: (c) 2017 Kornah BA, et al. This is an open-access article distributed under the terms of the creative commons attribution license, which permits unrestricted use, distribution, and reproduction in any medium, provided the original author and source are credited.

\begin{abstract}
Aim of study: To demonstrate clinical and radiological effectiveness of intramedullary fixation of closed diaphyseal humeral fractures in adults using the elastic stable intramedullary nail (ESIN).

Patients and methods: Between May 2011 and December 2013, twenty-eight patients (19 males) with closed diaphyseal humeral fractures treated with closed reduction and percutaneous fixation with 2 elastic stable nails. Age from 18 to 56 years (mean, 29 years). Patients with open or pathological fractures, those less than 18 years and medically unfit patients were excluded. Causative injury was pedestrian vehicular accident in 15, fall from height 9 and sport-related activity 4 patients. The time of surgical intervention varied from 24 to 72 hours post-injury.

Results: Patients were followed up 12-31 months with an average of 20 months. X-ray films showed that twentysix fractures united completely at a range 14-20 week (mean, 13.1 weeks). Twenty-Six cases healed in good alignment at a median time of 13.1 weeks (range 14-20 weeks). One case developed delayed union where bone marrow injection and longer immobilization till full healing done. One case developed non-union which was treated by bone grafting and plating. There were no intraoperative complications. One patient with preoperative radial nerve injury recovered spontaneously by eight weeks. Patients followed and assessed using Disabilities of the Arm, Shoulder and Hand score (DASH). At last follow-up, the average DASH score was 90.5 (range 60-100). Final clinical evaluation showed 17 cases Excellent, 8 cases Good, 2 cases fair and one case Poor according to previous score.
\end{abstract}

Conclusion: Elastic stable nail fixation is a good procedure for treating adult humeral shaft fractures in which stabilization is indicated as it provides stable fixation, with minimal soft tissue stripping at the fracture site and allows early mobilization of the extremity.

Keywords: Elastic nails; Diaphyseal humeral fractures; Nail fixation; Bone marrow; Injury

\section{Introduction}

Humeral shaft fracture is a common event, and representing between $3 \%$ and $5 \%$ of all skeletal fractures in adults [1]. The optimal management of these fractures has changed dramatically over the previous three decades from almost universal use of cast immobilization to a variety of operative interventions. Recent trend in most of displaced and segmental fractures is to treat them surgically [2]. Malunion and minor degrees of shortening of humeral shaft fractures can be tolerated owing to the wide range of motion of the shoulder and elbow with minor functional deficit [3]. New implants and recent techniques have been developed to modulate the indications, overcome incidence of treatment failure and to minimize complications and disabilities following injury. One of these implants is elastic stable intramedullary nails [4]. In our study we are going to evaluate the effectiveness, clinical and functional outcome of the diaphyseal humeral fracture treated by elastic stable intramedullary nails.

\section{Patients and Methods}

Ethical clearance was obtained from the institutional ethics committee and written consent from all patients was obtained. Patients were enrolled between May 2010 and December 2013. Twenty-Eight patients (19 males) between ages of 18 to 56 years (average, 29 years) with diaphyseal fracture of humerus had been treated by closed reduction and percutaneous fixation with intramedullary elastic stable nails. All fractures were closed, diaphyseal at different levels of humerus. The right side affected in 17 cases (60.7\%). No patient had bilateral fractures. Inclusion criteria involved: Male and female of age between 18 to 56 years with closed diaphyseal fracture of humerus who were medically fit for surgery. Exclusion criteria involved patients who were medically unfit for surgery, less than 18 or over 56 years old, open and pathological fractures, fractures extending to the articular margins of the shoulder or elbow and patients unwilling to participate in the study. Causative trauma was a pedestrian vehicular accident in 15 patients, fall from height 9 and sport-related activity in the remaining four patients. One patient had radial nerve injury and it was neurapraxia which recovered function spontaneously within eight weeks after injury. Patients were evaluated at 2-week, 6 weeks, 3 
Citation: Kornah BA, Soltan AA, Abdel-AAI MA (2017) Elastic Stable Intramedullary Nailing for Closed Diaphyseal Fractures of Humerus in

months, 6 months. Functional evaluation at follow up utilized DASH

Score. Distribution of patient's characteristics shown in Table 1.

\begin{tabular}{|c|c|c|c|c|c|c|c|c|}
\hline No. & Age & Gender & Side & Trauma & F-U & Union & Complications & Dash S. \\
\hline 1 & 20 & M & Lt. & M.C.A & 26 & $12 w$ & ------------------- & 100 \\
\hline 2 & 44 & M & Rt. & $\mathrm{FFH}$ & 18 & $12 w$ & ------------------- & 87 \\
\hline 3 & 30 & $\mathrm{~F}$ & Rt. & Sport. Inj. & 20 & $13 w$ & 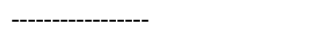 & 98 \\
\hline 4 & 25 & M & Lt. & M.C.A & 30 & $28 w$ & Delayed union, E-pain & 65 \\
\hline 5 & 23 & M & Rt. & FFH & 19 & $13 w$ & --_-1 & 98 \\
\hline 6 & 33 & M & Lt. & M.C.A & 20 & $14 \mathrm{w}$ & Superficial infection-E-pain & 96 \\
\hline 7 & 18 & M & Rt. & FFH & 24 & $12 \mathrm{w}$ & Radial N. & 66 \\
\hline 8 & 37 & M & Rt. & M.C.A & 20 & $13 \mathrm{w}$ & 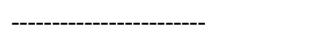 & 93 \\
\hline 9 & 21 & $\mathrm{~F}$ & Lt. & M.C.A & 24 & $12 \mathrm{w}$ & 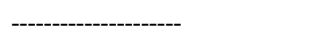 & 79 \\
\hline 10 & 47 & $\mathrm{~F}$ & Lt. & $\mathrm{FFH}$ & 25 & $14 \mathrm{w}$ & Superf. infection & 95 \\
\hline 11 & 20 & M & Rt. & M.C.A & 21 & $12 \mathrm{w}$ & 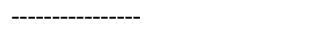 & 98 \\
\hline 12 & 38 & M & Rt. & Sport. Inj. & 20 & $12 \mathrm{w}$ & Nail migration & 86 \\
\hline 13 & 29 & M & Lt. & FFH & 19 & $13 \mathrm{w}$ & --.-- & 88 \\
\hline 14 & 56 & $\mathrm{~F}$ & Rt. & M.C.A & 18 & $14 \mathrm{w}$ & ----о-о-о-о-- & 100 \\
\hline 15 & 18 & M & Rt. & FFH & 20 & $15 w$ & 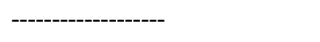 & 87 \\
\hline 16 & 19 & M & Lt. & M.C.A & 25 & $12 \mathrm{w}$ & Superf, infection & 100 \\
\hline 17 & 39 & $\mathrm{~F}$ & Rt. & M.C.A & 18 & $14 w$ & E-pain & 88 \\
\hline 18 & 18 & M & Lt. & Sport. Inj. & 30 & $20 \mathrm{M}$ & N-U,E-pain, ROM & 60 \\
\hline 19 & 22 & $M$ & Rt. & $\mathrm{FFH}$ & 19 & $12 w$ & 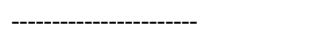 & 99 \\
\hline 20 & 26 & $\mathrm{~F}$ & Rt. & M.C.A & 22 & $20 w$ & Limited ROM elbow, E-pain & 88 \\
\hline 21 & 49 & M & Lt. & M.C.A & 28 & $14 \mathrm{w}$ & Limited ROM & 97 \\
\hline 22 & 19 & M & Rt. & Sport. Inj. & 18 & $12 \mathrm{w}$ & 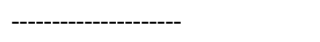 & 96 \\
\hline 23 & 35 & $\mathrm{~F}$ & Lt. & FFH & 23 & $14 \mathrm{w}$ & 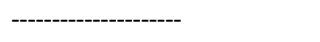 & 93 \\
\hline 24 & 21 & $\mathrm{~F}$ & Rt. & M.C.A & 21 & $12 w$ & E-pain & 86 \\
\hline 25 & 29 & M & Rt. & M.C.A & 23 & $14 w$ & 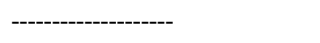 & 95 \\
\hline 26 & 30 & M & Lt. & FFH & 19 & $12 \mathrm{w}$ & 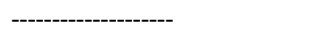 & 98 \\
\hline 27 & 21 & M & Rt. & M.C.A & 17 & $15 w$ & E-pain & 98 \\
\hline 28 & 25 & $\mathrm{~F}$ & Rt. & M.C.A & 29 & $12 \mathrm{w}$ & & 100 \\
\hline
\end{tabular}

Table 1: Distribution of patient's characteristics.

The operation was done within 24-72 hours following admission. Operative procedures were carried out under general anesthetic in 19 and regional anesthesia in 9 patients. With the patient in supine position, the affected upper limb was supported by a radiolucent arm table with the shoulder abducted 900 and the elbow flexed to 900 . An image intensifier was positioned so that the long axis of the humerus was in view and surface markings were made on the skin for the fracture site and proximal and distal fragments. The nail thickness was selected according to the narrowest diameter of the medullary canal on radiographs using the formula $0.4 \times$ diameter of the canal in $\mathrm{mm}$. 
Citation: Kornah BA, Soltan AA, Abdel-AAI MA (2017) Elastic Stable Intramedullary Nailing for Closed Diaphyseal Fractures of Humerus in Adults. A Case Series of 28 Patients. J Trauma Treat 6: 400. doi:10.4172/2167-1222.1000400

Page 3 of 6

Closed reduction done for all patients through longitudinal traction with abduction and external rotation of the arm. An image intensifier was used to assess quality of reduction.

Two drill holes were done along the lateral supracondylar ridge $2-3 \mathrm{~cm}$ proximal to olecranon fossa to get good purchase through the solid columns of bone in the distal humerus. The first nail was introduced through the inferior hole and passed upwards towards the fracture site. The second one introduced and advanced to the fracture site. Once reduction achieved, both nails were advanced across the fracture site up to proximal metaphysis. Bending of the two nails distally was done and cut $1 \mathrm{~cm}$ from the cortical surface for easy removal later. The wounds were closed. Post-operatively a collar and cuff sling applied to the operated arm for three weeks during which patients were encouraged to start pendulum exercises of the shoulder as soon as comfortable. Cuff was discarded after 4 weeks.

The average time of hospitalization was 2-5 days. Radiographs were typically obtained immediate postoperative, 2 weeks postoperatively to check for loss of reduction, 6,12 and 24 weeks postoperatively to evaluate union and alignment status of the fracture. The average follow-up was 22 months (range 18-33 months).

Removal of implant was performed (under general anesthesia as a day case procedure) after complete union of fracture.

\section{Case Presentation}

Male patient 35 years. Sustained motor car accident. He got oblique fracture mid shaft left humerus with butterfly fragment (Figures 1 and 2). Closed reduction and 2 elastic stable intramedullary nails via lateral supracondylar ridge approach (Figure 3). Fracture united completely within 14 weeks (Figures 4-8).

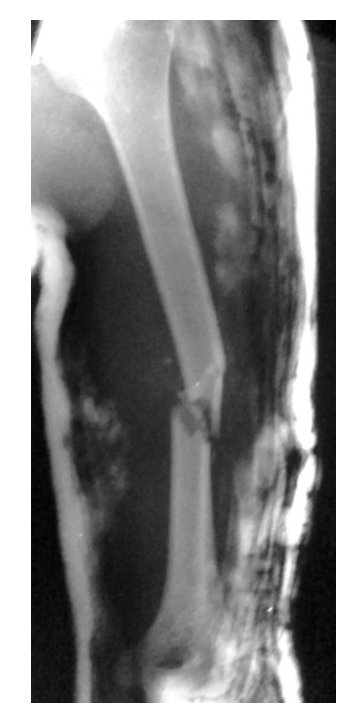

Figure 1: AP view pre-operative radiography fracture shaft Lt. humerus.

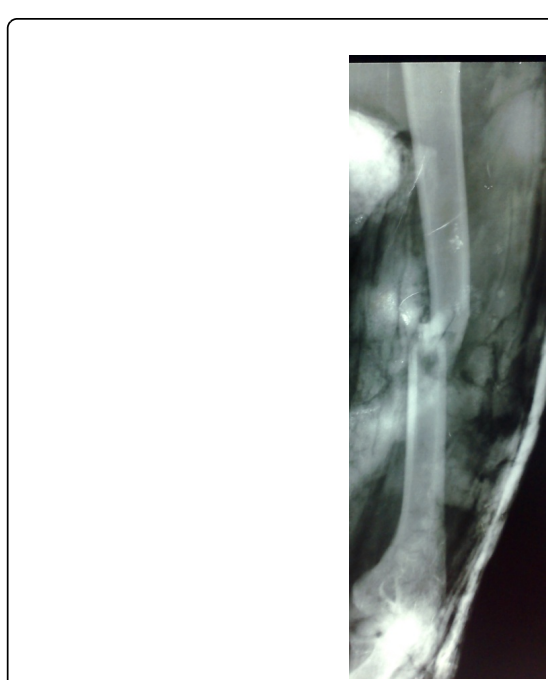

Figure 2: Lateral view pre-operative radiography fracture shaft Lt. humerus.

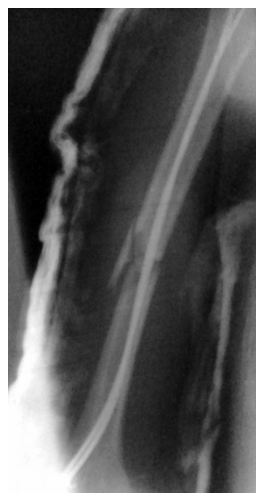

Figure 3: Immediate post-operative. Good reduction achieving good alignment.

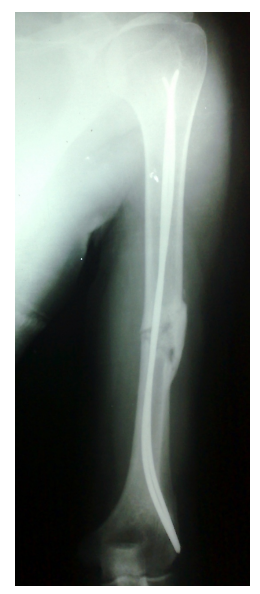

Figure 4: 8 weeks post-operative with good union of fracture. 
Citation: Kornah BA, Soltan AA, Abdel-AAI MA (2017) Elastic Stable Intramedullary Nailing for Closed Diaphyseal Fractures of Humerus in Adults. A Case Series of 28 Patients. J Trauma Treat 6: 400. doi:10.4172/2167-1222.1000400

Page 4 of 6

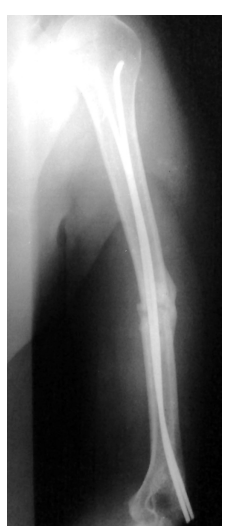

Figure 5: 10 weeks post-operation with full union of fracture.

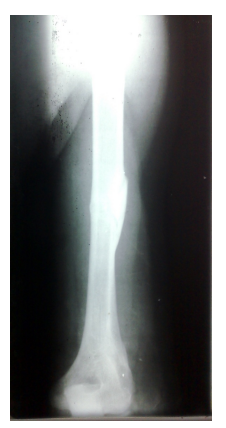

Figure 6: After 14 weeks post-operation.

\section{Results}

All patients had acceptable reduction with less than $10^{\circ}$ angulations in either plane. Complete union achieved in twenty-six patients (92.8\%) at a mean time of 13.1 weeks (range 14 to 20 weeks). Healing was defined as cortical contiguity in all four cortices seen on standard anteroposterior (AP) and lateral radiographs of the humerus. One patient (3.6\%) showed delayed union (case No. 4). Three bone marrow injections with two weeks interval was done and union achieved over 28 weeks. One patient (3.6\%) had non-union (case NO.18) and was treated by plating and bone grafting while maintaining the nails in situ. Twenty-five patients (89.3\%) regained full range of motions for both shoulder and elbow joints. Three patients $(10.7 \%)$ lacked $10^{\circ}$ of extension and $10^{\circ}$ of flexion of elbow joint following healing at final evaluation (cases No. 18,20,21). Superficial infection developed in two patients (cases No. 6,10) and managed by daily dressing and antibiotics. No patient developed deep infection. Twenty-two patients (78.6\%) had no shoulder or elbow pain at final clinical evaluation. Six patients (21.4\%) had some elbow discomfort (cases No. 6, 17, 18, 20, $24,27)$ which was tolerable and not affecting daily activities of patient.

One patient (3.6\%) had preoperative radial nerve injury (case No. 7) that recovered spontaneously within ten weeks after injury. Distal migration of nails occurred just in one patient (3.6\%) (case No. 12). Patient returned back to the operating room and the nails were rehammered to sit flush and trimmed to avoid skin irritation.

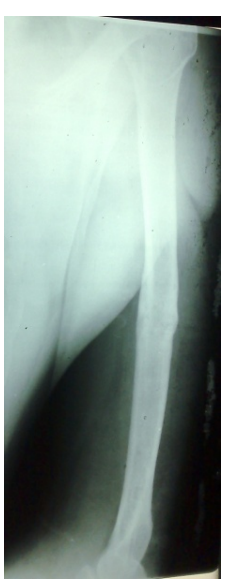

Figure 7: 14 weeks post-op. after extraction of nails (Lateral view).
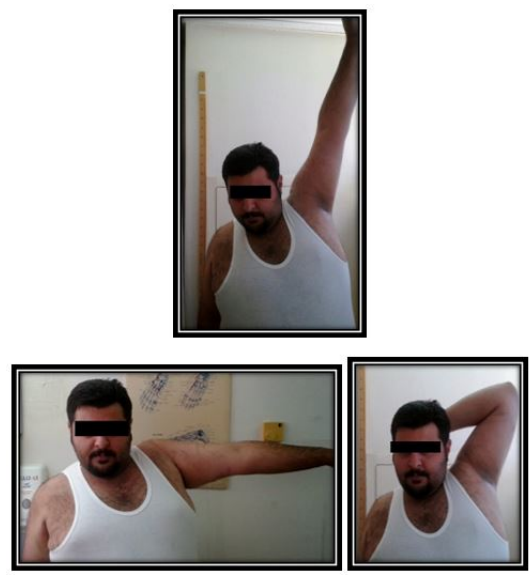

Figure 8: The three photos demonstrates full functional activity of shoulder and elbow joints.

\begin{tabular}{|c|c|c|c|}
\hline Result & No. cases & complication & Case Number \\
\hline Union & 26 united & $\begin{array}{l}\text { Delayed-union...1 case } \\
\text { Non-union........1 case }\end{array}$ & 4,18 \\
\hline Range of Motion & 25 full ROM & $\begin{array}{l}\text { Limited } \quad \text { elbow......3 } \\
\text { Cases }\end{array}$ & $18,20,21$ \\
\hline Pain & 22 No pain & Elbow pain.....6 Cases & $\begin{array}{l}6,17,18,20 \\
24,27\end{array}$ \\
\hline Superficial Infection & $\begin{array}{ll}25 & \text { No } \\
\text { infection }\end{array}$ & Infection 2 cases & 6,10 \\
\hline $\begin{array}{l}\text { Complications: } \\
\text { Radial N injury }\end{array}$ & 27 No injury & Radial $\mathrm{N}$ injury 1 case & 7 \\
\hline Distal Migration & 27 without & $\begin{array}{l}\text { Distal nail migration } 1 \\
\text { case }\end{array}$ & 12 \\
\hline
\end{tabular}

Table 2: Distribution of cases' results. 
No patients had implant failure. On final follow-up, the mean DASH score was 90.5 (range 60 to 100 ) and accordingly we had 17 patients $(60.7 \%)$ rated Excellent, $8(28.6 \%)$ patients rated Good 2 (7.1\%) patients rated Fair and one patients (3.6\%) rated poor. distribution of results shown in Table 2.

\section{Discussion}

Management of diaphyseal fractures of humerus in adults remains a challenging issue for orthopedic surgeons. Non-operative treatment still considered an option $[5,6]$ and union rates of more than $90 \%$ are often reported [4,5]. Acceptable alignment of humeral shaft fractures is considered to be $3 \mathrm{~cm}$ of shortening, $30^{\circ}$ of varus/valgus angulation, and $20^{\circ}$ of anterior/posterior angulations. Varus/valgus angulation is tolerated better proximally, and more angulations may be tolerated better in patients with obesity $[7,8]$. There is no universal agreement on optimal modality of fixation when surgical intervention is chosen [9]. Plating carries the risk of infection, neurological insults and non-union $[10,11]$.

Rigid intramedullary nailing whether used via antegrade or retrograde entry still a debatable issue. The proximal entry for antegrade nailing may lead to rotator cuff injury, shoulder impingement, proximal nail migration and impaired shoulder function. On the contrary distal entry portal above olecranon fossa for retrograde nailing may lead to supracondylar fractures, triceps tendon irritation, heterotopic bone formation and elbow pain [12]. A biomechanical study states that distal entry points for retrograde nailing lead to reduction in the torque and energy absorbed to failure and the weakening increases if the entry point is the olecranon fossa compared to the metaphyseal triangle [13].

Elastic internal fixation; contrary to rigid fixation, needs some degree of relative movement to promote formation of the external callus, which is the physiological callus that forms most rapidly, and has the highest biomechanical strength. Also, elastic stable nails preserve the endosteal blood supply and this gives us the option of plating the humerus with non-union in our study without extracting the nails. The minimally invasive procedure with preservation of soft tissues, periosteum and fracture haematoma allows prompt biological union. In our series union achieved in $92.8 \%$ of patients by following these rules [14].

A retrospective study treating closed humeral shaft fractures with titanium elastic nail, all the fractures healed in good alignment with no intraoperative complications including neurological injury, vascular injury and infection [15]. In a series of diaphyseal fracture of humerus using titanium elastic nail and at the end of the study the authors concluded that the titanium elastic nails offer a number of potential advantage over traditional way of treating long bone fracture including early immobilization, shorter hospital stay and less risk of loss of fracture position [16]. In two comparative studies treating closed diaphyseal fractures humerus with elastic nail and plate osteosynthesis, the authors concluded that elastic stable nail is applicable for routine use in appropriate selected humerus shaft fracture $[17,18]$.

In our series all the patients were managed by Elastic stable intramedullary nails (ESIN) as a method of fixation and utilizing retrograde lateral epicondylar entry. By this approach, it is possible to avoid supra-olecranon entry complications $[1,3,15,16]$. Also, neural problems of dual entry through medial and lateral points could be overcome [19]. Great attention should be paid for such entry and proper opening of the cortex should be done to avoid supracondylar humeral fractures or neural injury.

The results in our series showed almost similar range of movements of the shoulder and elbow joints as compared to the contralateral nonoperated limb in 25 patients (89.3\%). The use of lateral epicondylar entry would avoid breaching the elbow joint and preserving the joint motion. The three cases with limited elbow ranges of motion mostly caused by prolonged immobilization due to delayed union (one case), non-union (one case) and the third case due to joint discomfort, rather than joint stiffness. Our series did not have any post-operative nerve injuries or deep infections, and this attributed to the minimal invasive procedure we utilized which respects largely the soft tissues. Also, our series showed low complication rate as we considered well the biomechanical principles of elastic intramedullary nailing principles.

\section{Conclusion}

The use of elastic stable intramedullary nailing (ESIN) for treating closed diaphyseal fractures of humerus is an acceptable method of internal fixation. It presents consistent series of advantages, including: physiological consolidation, flexible stability, and compliance for the patient. Also, it carries a low complication rate if attention is paid to biomechanical principles. The procedure is minimally invasive, simple and well reproducible technique with a steep learning curve. Because of the excellent objective and subjective results, the operative stabilization of humeral shaft fractures with ESIN should be recommended to adult patients.

\section{References}

1. Micheal R, Mckel D (2006) Title: Rockwood and greens fracture in adults. Bucholz RW, Court-Brown CM, Heckman JD, Tornetta P (eds). Lippincott Williams and Wilkins, USA. (7th edn.) 6 chapter 30 page 1119.

2. Furlan D, Pogorelić Z, Biočić M, Jurić I, Budimir D, et al. (2011) Elastic stable intramedullary nailing for pediatric long bone fractures: Experience with 175 fractures. Scand J Surg 100: 208-215.

3. Crenshaw AH (1998) Shaft of humerus. In: Canale ST (ed). Campbell's operative orthopaedics (9th edn) St Louis, Mo: Mosby. pp. 2296-2309.

4. Marchetti PG, Vicenzi G, Impallomeni C, Landi S, Surdo V (2000) The use of elastic nails for intramedullary fixation of humeral fractures and nonunions. Orthopedics 23: 343-347.

5. Ward EF, Savoie FH, Hughes JL (1998) Fractures of the diaphyseal humerus. In: Browner BD, Jupiter JB, Levine AM (eds). Skeletal trauma: Fractures, dislocations, ligamentous injuries (2nd edn) Philadelphia, Pa: WB Saunders, USA. pp. 1523-1547.

6. Sarmiento A, Zagorski JB, Zych GA, Latta LL, Capps CA (2000) Functional bracing for the treatment of fractures of the humeral diaphysis. J Bone Joint Surg Am 82: 478-486.

7. Klenerman L (1966) Fractures of the shaft of the humerus. J Bone Joint Surg Br 48: 105-111.

8. Xie F, Wang S, Jiao Q, Shen Y, Ni XY, et al. (2011) Minimally invasive treatment for severely displaced proximal humeral fractures in children using titanium elastic nails. J Pediatr Orthop 31: 839-846.

9. Rosenbaum A, Uhl R (2012) Nonunion of humeral shaft fractures following flexible nailing fixation. Orthopedics 35: 512-515.

10. Kumar M, Kaushik YS (2017) Functional outcome of humerus shaft fractures in adults treated by flexible nails using retrograde technique. IJOS 3: 176-178.

11. Sheng ZJ (2012) Elastic intramedullary nailing for children with fracture of shaft of humerus. J Clin Orthop 5: 44-49.

12. Abosalim AA, Shams El-Din AS, El-Mowafy HM (2015) Treatment of humeral shaft fractures by a single elastic stable intramedullary nail in children. Menoufia Medical J 8: 125-132. 
Citation: Kornah BA, Soltan AA, Abdel-AAI MA (2017) Elastic Stable Intramedullary Nailing for Closed Diaphyseal Fractures of Humerus in Adults. A Case Series of 28 Patients. J Trauma Treat 6: 400. doi:10.4172/2167-1222.1000400

Page 6 of 6

13. Strothman D, Templeman DC, Varecka T, Bechtold J (2000) Retrograde nailing of humeral shaft fractures: a biomechanical study of its effects on strength of the distal humerus. J Orthop Trauma 14: 101-104.

14. Knorr P, Joeris A, Lieber J, Schalamon J, Dietz H (2005) The use of ESIN in humerus fractures. Eur J Trauma 31: 12-18.

15. Garg S, Dobbs MB, Schoenecker PL, Luhmann SJ, Gordon JE (2009) Surgical treatment of traumatic humeral diaphyseal fracture with titanium elastic nails. J Child Orthop 3: 121-127.

16. Carroll EA, Schweppe M, Langfitt M, Miller AN, Halvorson JJ (2012) Management of humeral shaft fractures. J Am Acad Orthop Surg 20: 423-433.
17. Heineman DJ, Poolman RW, Nork SE, Ponsen KJ, Bhandari M (2010) Plate fixation or intramedullary fixation of humeral shaft fractures. Acta Orthop 81: 218-225.

18. Chen F, Wang Z, Bhattacharyya T (2013) Outcomes of nails versus plates for humeral shaft fractures: A medicare cohort study. J Orthop Trauma 27: 68-72.

19. Verga M, Peri Di Caprio A, Bocchiotti MA, Battistella F, Bruschi S, et al. (2007) Delayed treatment of persistent radial nerve paralysis associated with fractures of the middle third of humerus: Review and evaluation of the longterm results of 52 cases. J Hand Surg Eur 32: 529-533. 